\title{
岩石の強度と弾性波速度の関係に関する 確率論的研究
}

\author{
大久保誠介 ${ }^{1}$
}

西 松 裕 ${ }^{2}$

\section{1. はじめに}

彈性波速度（音波速度）の測定結果より岩石の物理的性 質を推定しようとする試みは，以前よりいろいろな分野で 検討されてきており，実際たとえば速度検層などで害用に 供されている。この方法は巨視的な割れ目の存在や, 岩石 の空吵率を推定するには極めて有効であり，かなり広い範 囲の岩石 (岩艋) の性質を能率よく調べられる点で, 他の 方法より勝つているといえよう。また，近年のめざましい 測定技術の発達により, 高精度の測定が可能となり, 今後 より多方面で利用されるものと期待されている。

巨視的な割れ目の存在は別にしても, 一般に岩石は多数 のクラックを含み, その物理的性質はクラックの性状によ り大きく左右されることがしられている。岩石の空隙率あ るいは密度と彈性波速度の関連については, 多くの実験結 果が報告されており 理論的にもある程度の説明がなされ

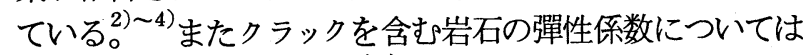
Wal shなどの研究がある。 の引張破壊は, 微小なクラック (Griffith Crack) の不 安定な成長によるものであり, 引張強度は含まれるクラッ クの寸法, 形状等により変化することがしられている。

しかし, 彈性波速度あるいは空吵率と強度との関係につ いては, 不明な部分が多い。空吵率の大きい場合には, 空 吵の存在による強度低下を有効断面積の減少によるものと して説明できるが, 空隙率の比較的小さい岩石の場合には, 定説のないのが現状である。他方, 岩石の彈性波速度と強 度の間に密接な関連のあることはよくしられており, 岩石 （岩質）の分類が彈性波速度の測定值を利用して行なわれ ることがあるものの, 理論的検討は従来ほとんど行なわれ ていない。

本研究ではこのような点を考慮して, 空吵率の比較的小 さい岩石の緃波伝ぱ速度と引張強度との関係を理論, 実 験の両面より検討した。すなわち, まずクラックの存在が 縱波伝ぱ速度および引張強度に大きな影響を及ぼすことを 考慮して, クラックを含む岩石における両者の関係を線形 破壊力学, 確率過程論を利用して理論的に検討した。また 頁岩を用いて実験を行ない，理論結果の検証を行なつた。 さらに縱波伝ぱ速度と庄縮強度との関係についても, 理論,

* 1979 年 5 月 16 日受理

1. 正会員 工博 東京大学助教授 工学部資源開発工学科

2. 正会員 工博 東京大学教授工学部資源開発工学科
実験の両面より検討した。

\section{2. クラックを含む岩石の空隚率と縦波伝ぱ速度}

等方かつ均質な線形彈性体とみなせる岩石 (母材) 中に, クラックが存在する場合を考えることにする。簡単のため クラックはFig.1に示すように扁平な円板状をしており， その径を $2 a$ また厚さを $2 b$ と書くことにする。また, 球 面座標 $(\varphi, \theta)$ を用いて, クラックの確率密度関数が次 のように書けるものと仮定する。

$$
n(a, \alpha, \theta, \varphi)=N \cdot n_{1}(a) \cdot n_{2}(\alpha) \cdot n_{3}(\theta, \varphi)^{\mathrm{a})}
$$

ただしNは単位体積中に含まれるクラックの数である。 クラックの体積を径が $2 a$ で扁平度が $\alpha(=b / a)$ のだ円 体の体積 $\left(=4 \pi a^{3} \alpha / 3\right)$ で近似することにし, $\theta$ が $\theta$ と $\theta+d \theta, \varphi$ が $\varphi$ と $\varphi+d \varphi$ との間にある立体角要素が

$\sin \varphi d \theta d \varphi$ であることを考慮して積分すれば, 空隙率 入は次のように書き表わすことができる。

$$
\left.\begin{array}{l}
\lambda=\int_{0}^{\infty} d a \int_{0}^{1} d \alpha \int_{0}^{2 \pi} d \theta \int_{0}^{\frac{\pi}{2}} C d \varphi \\
C=\frac{4 \pi a^{3}}{3} \alpha N n_{1}(a) n_{2}(\alpha) n_{3}(\theta, \varphi) \sin \varphi
\end{array}\right\}
$$

次にクラックを含む岩石のコンプライアンスについて考 えてみることにする。クラックを含ま㛧石およびクラッ クを 1 個含む岩石の $i$ 方向のコンプライアンスをそれぞれ $S_{0}, S_{i i}$ とすれば, 近似的に次式が成り立つ。

$$
\left.\begin{array}{l}
S_{i i} \equiv S_{0}\left(1+D_{i i}\right) \\
D_{i i} \approx \lambda \frac{4}{\pi \alpha} \cos ^{2} \varphi
\end{array}\right\}
$$

この場合, $\varphi$ はクラック法 線と $i$ 方向とのなす角度であ る。したがつて, 多数のクラ ックが確率密度関数 $n(a$, $\alpha, \theta, \varphi)$ にしたがつて岩 石中に分布している場合には， $i$ 方向のコンプライアンスの 変化率 $D_{i i}$ は次のように書け る。
a) $\int_{0}^{\infty} n_{1}(a) d a=1$, $\int_{0}^{1} n_{2}(\alpha) d \alpha=1$, $\int_{0}^{2 \pi} d \theta \int_{0}^{\frac{\pi}{2}} n_{3}(\theta, \varphi) \sin \varphi d \varphi=1$ とする。

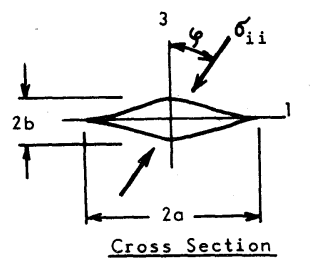

Fig. 1 Penny-shaped crack.

日本鉱業会誌/96 1109 ('80-7) $449<11>$ 


$$
D_{i i}=\int_{0}^{\infty} d a \int_{0}^{1} d \alpha \int_{0}^{2 \pi} d \theta \int_{0}^{\frac{\pi}{2}} C \frac{4}{\pi \alpha} \cos ^{2} \varphi d \varphi
$$

これを整理すれば次式が得られる。

$$
\left.\begin{array}{rl}
D_{i i} & =\frac{16}{3} N \overline{a^{3}} \Phi_{i i} \\
\overline{a^{3}} & =\int_{0}^{\infty} n_{1}(a) a^{3} d a \\
\Phi_{i i} & =\int_{0}^{2 \pi} d \theta \int_{0}^{\frac{\pi}{2}} n_{3}(\theta, \varphi) \sin \varphi \cos ^{2} \varphi d \varphi
\end{array}\right\}
$$

$i$ 方向のバー・ベロシティ $V_{i i}$ とコンプライアンス $S_{i i}$ の 間には次式の関係が成り立つ。

$$
V_{i i}=\sqrt{\frac{1}{S_{i i} \rho}}
$$

ただしのは密度である。したがつて母材のバー・ベロシ ティを $V_{0}$, 密度を $\rho_{0}$ とすれば次式が得られる。

$$
D_{i i}=\frac{S_{i i}}{S_{0}}-1=\frac{V_{0}^{2} \rho_{0}}{V_{i i}^{2} \rho}-1
$$

比較的空吵率の小さい時, したがつてのがの $\rho_{0}$ とままり異 ならない時には近似的に次式が成り立つ。

$$
D_{i i} \approx \frac{V_{0}^{2}}{V_{i i}{ }^{2}}-1
$$

また，(1)，(2)式より空吵率とコンプライアンスの変化率 の間には次の関係の成り立つことがわかる。

$$
\begin{aligned}
& \lambda=k_{i i} D_{i i} \\
& k_{i i}=\frac{\pi}{4} \quad \frac{\bar{\alpha}}{\Phi_{i i}}
\end{aligned}
$$

ただし が得られる。

$$
\lambda=k_{i i}\left(\frac{V_{0}^{2}}{V_{i i}^{2}}-1\right)
$$

\section{3. クラックを含む岩石の強度}

あるクラックの破壊発生の速度定数 $\tau$ を次のように仮定 する。?

$$
\tau=L \sigma_{L}^{\delta}
$$

ただし，Lおよび $\delta$ は材により決まる定数であり， $\delta_{L}$ はクラック外縁での局所応力の最大值である。

遠方で一様な一軸引張応力 $\sigma_{i i}$ が $i$ 方向に加えられた時 を考える。この時, 円板状クラック外縁での応力拡大㐿数 $K_{\mathrm{I}}, K_{\mathrm{II}}, K_{\mathrm{III}}$ はFig.1 の記号を使つて次のように表わさ れる。

$$
\left.\begin{array}{l}
K_{\mathrm{I}}=\frac{2}{\pi} \sigma_{i i} \cos ^{2} \varphi \sqrt{\pi a} \\
K_{\mathrm{II}}=\frac{4 \cos \xi}{\pi(2-\nu)} \sigma_{i i} \frac{\sin 2 \varphi}{2} \sqrt{\pi a} \\
K_{\text {III }}=\frac{4(1-\nu) \sin \xi}{\pi(2-\nu)} \sigma_{i i} \frac{\sin 2 \varphi}{2} \sqrt{\pi a}
\end{array}\right\}
$$

ただし，レはポアソン比である。(8)式より明らかなよう に応力拡大係数はいずれも $\sigma_{i i} \sqrt{a}$ に比例し, さらに $\varphi$ が 与えられれば円板状クラック外縁の任意の位置 ( $\xi$ ) での

b ）比較的空隙率の小さい範囲内では, ポアソン比はほとんど変化しな い。このような場合には，(4)式の関係は無限体中の縱波伝ぱ速度に 対しても成立する。
応力払大俰数が計算できる。一方, 線形破壊力学の成立す る範囲，すなわち重ね合せの原理の成り立つ時には, クラ ック端近傍での局所応力は $K_{\mathrm{I}}, K_{\mathrm{II}}, K_{\mathrm{III}}$ の線形は関数に よつてあらわされる。したがつて任意の位置Qでの局所応 カのは, 次のように表わされる。

$$
\sigma=g_{1}(Q) \sqrt{a} \sigma_{i i} g_{2}(\varphi)
$$

$g_{1}(Q)$ の最大値を $g_{1 \text { max }}$ として, 局所応力の最大值 $\sigma_{L}$ は次式となる。

$$
\sigma_{L}=g_{1 \max } \sqrt{a} \quad \sigma_{i i} g_{2}(\varphi)
$$

あるいは, $l(\varphi)$ をのみの関数として次式のようにあ らわされる。

$$
\sigma_{L}=\sqrt{a} \sigma_{i i} l(\varphi)^{\mathrm{c})}
$$

(9)式を(7)式に代入して次式が得られる。

$$
\tau=L\left\{\sqrt{a} \sigma_{i i} l(\varphi)\right\}^{\delta}
$$

破壊き裂の発生が一段のPoi isson 過程, すなわち速度定 数 $\tau_{j}$ のクラックから破壊き裂が発生するまでの時間が $t$ よ り大きい確率 $P\left(t \mid \tau_{j}\right)$ が次式で与えられるものとする。

$$
P\left(t \mid \tau_{j}\right)=\exp \left(-\tau_{j} t\right)
$$

1 個の試験片に含まれる $n$ 個のクラックは同一母集団に 属し, 各クラックからの破壊き裂発生は独立事象であると 考えら机る。ぜ、性材料の引張破壊の場合について考えれ ば，破壊き裂の発生が直ちに巨視的破壊をもたらすと考え てよいので, 試験片が時刻 $t$ までに破壊しない確率 ( 生存 確率) は次式で与えられる。

$$
P_{n}(t)=\prod_{j=1}^{n} P\left(t \mid \tau_{j}\right)
$$

$n$ が十分大きい時には大数の法則を使つて上式は次の ように近似される。

$$
\left.\begin{array}{l}
P_{n}(t) \approx \exp \left(-n \tau_{m} t\right) \\
\tau_{m}=\int_{0}^{\infty} d a \int_{0}^{2 \pi} d \theta \int_{0}^{\frac{\pi}{2}} L \sigma_{L}^{\delta} n_{1}(a) n_{3}(\theta, \varphi) \sin \varphi d \varphi
\end{array}\right\}
$$

クラック長の分布に関して, 今までのところ詳しいこと はわかつていないので，ここでは一応次式のように確率密 度関数を仮定して議論を進めることにする。

$$
n_{1}(a)=A m a^{m-1} \exp \left(-A a^{m}\right)^{\mathrm{d})} \quad \ldots \ldots \ldots \text { (13) }
$$

応力速度 $\dot{\sigma}_{i i}$ が一定という条件下で, すなわち $\sigma_{i i}=$ $\dot{\sigma}_{i i} t$ として(13)式を(12)式に代入し，(9)式を考慮して変形, 整理をすれば次式が得られる。

$$
\left.\begin{array}{l}
P_{n}\left(\sigma_{i i}\right)=\exp \left\{-L_{i i} N A^{-\frac{\delta}{2 m}} \sigma_{i i}{ }^{\delta+1}\right\} \\
L_{i i}=L \frac{v}{\dot{\sigma}_{i i}} \frac{m}{m+\frac{\delta}{2}} \Gamma\left(2+\frac{\delta}{2 m}\right) \int_{0}^{2 \pi} d \theta \int_{0}^{\frac{\pi}{2}} l(\varphi)^{\delta} \\
\times n_{3}(\theta, \varphi) \sin \varphi d \varphi
\end{array}\right\}
$$

ただし，vは試験片体積である。したがつで $i$ 方向の引

c) : 局所応力の最大值としてどのような応力の最大値, たとえば引張応 力あるいはせん断応力の最大値をとるかは議論のある所であるが, いずれにしろ局所応力の最大值は(9)式の形で表わされる。

d）（13）式で定義される確率分布をWeibull 分布といい, 式中 $A, m$ はともにパラメータである。mはふうう均一性係数と呼ばれ， $m$ の 值が大きい程均一度が高い。 
張強度の平均値 $T_{i i}$ は次のようになる。

$$
\begin{aligned}
& T_{i i}=L_{i i}{ }^{-\frac{1}{\delta+1}} \Gamma\left(\frac{\delta+2}{\delta+1}\right) A^{\frac{1}{2 m} \frac{\delta}{\delta+1}} N^{-\frac{1}{\delta+1}} \cdots \cdots \text { (15) } \\
& \text { 一方, (13)式を仮定すれば, } \\
& \overline{a^{3}}=\frac{m}{m+3} \Gamma\left(2+\frac{3}{m}\right) A^{-\frac{3}{m}}
\end{aligned}
$$

であるので, この時の $D_{i i}$ は(2)式を使つて次のように書け る。

$$
D_{i i}=\frac{16}{3} \Phi_{i i} \frac{m}{m+3} \Gamma\left(2+\frac{3}{m}\right) A^{-\frac{3}{m}} N \quad \cdots(16)
$$

(15)，(16)式よりAを消去して整理すれば次式が得られる。

$$
\begin{aligned}
\log T_{i i}= & -\frac{1}{6} \frac{\delta}{\delta+1} \log D_{i i}+\left(\frac{1}{6} \frac{\delta}{\delta+1}-\frac{1}{\delta+1}\right) \\
& \times \log N-\frac{1}{\delta+1} \log L_{i i}+\frac{1}{6} \frac{\delta}{\delta+1} \\
& \times \log \left\{\frac{16}{3} \Phi_{i i} \frac{m}{m+3} \Gamma\left(2+\frac{3}{m}\right)\right\} \\
& +\log \left\{\Gamma\left(\frac{\delta+2}{\delta+1}\right)\right\} \quad \ldots \ldots \ldots \ldots \ldots \ldots(17)
\end{aligned}
$$

\begin{tabular}{|c|c|c|c|c|}
\hline & $\begin{array}{l}\text { Uniaxial } \\
\text { Compression } \\
\text { Test }\end{array}$ & $\begin{array}{l}\text { Brazilian } \\
\text { Test }\end{array}$ & $\begin{array}{l}\text { Direct } \\
\text { Shear } \\
\text { Test }\end{array}$ & $\begin{array}{l}\text { Ultrasonic } \\
\text { Velocity } \\
\text { Measurement } \\
\text { Test }\end{array}$ \\
\hline $\begin{array}{l}\text { Specimen Diameter } \\
(\mathrm{mm})\end{array}$ & 25 & 25 & 30 & 25 \\
\hline $\begin{array}{l}\text { Length-to-Diameter } \\
\text { Ratio }\end{array}$ & 2 & 0.5 & 1 & 2 \\
\hline $\begin{array}{l}\text { End Flatness } \\
\text { (tolerance in } \mathrm{mm} \text { ) }\end{array}$ & $\begin{array}{l}+0.02 \\
-0.02\end{array}$ & $\begin{array}{l}+0.05 \\
-0.05\end{array}$ & $\begin{array}{l}+0.02 \\
-0.02\end{array}$ & $\mathrm{NA}$ \\
\hline $\begin{array}{l}\text { Perpendicularity } \\
\text { of End Surfaces } \\
\text { to Specimen Axis } \\
\text { (tolerance in degree) }\end{array}$ & $\begin{array}{l}+0.5 \\
-0.5\end{array}$ & $\begin{array}{l}+2, \\
-2\end{array}$ & $\begin{array}{l}+0.5 \\
-0.5\end{array}$ & $\mathrm{NA}$ \\
\hline $\begin{array}{l}\text { Rate of Loading } \\
\text { (minutes until } \\
\text { failure) }\end{array}$ & $\begin{array}{l}\text { one to } \\
\text { fifteen }\end{array}$ & about five & about five & $\mathrm{NA}$ \\
\hline $\begin{array}{l}\text { Test Group } \\
\text { (number of specimens } \\
\text { per lot) }\end{array}$ & $\begin{array}{l}\text { five or } \\
\text { more }\end{array}$ & $\begin{array}{l}\text { five or } \\
\text { more }\end{array}$ & about ten & $\begin{array}{l}\text { five or } \\
\text { more }\end{array}$ \\
\hline
\end{tabular}

\begin{tabular}{|c|c|c|c|c|c|c|c|c|}
\hline & \multirow{2}{*}{$\begin{array}{l}\text { Vertical } \\
\text { Direction }\end{array}$} & \multicolumn{7}{|c|}{ Horizontal Directions } \\
\hline & & North & $30^{\circ}$ & $60^{\circ}$ & East & $120^{\circ}$ & $150^{\circ}$ & South \\
\hline $\begin{array}{l}\text { Longitudinal } \\
\text { Wave Velocity* } \\
\text { (km/sec) }\end{array}$ & 2.85 & 5.04 & 5.09 & 5.08 & 5.05 & 5.02 & 5.02 & 5.04 \\
\hline
\end{tabular}

(17)式において，mは変化しないものとし，また通常 $\delta \gg 1$ であるので近似的に次式が得られる。

$$
\left.\begin{array}{rl}
\log T_{i i} & =-\frac{1}{6} \log D_{i i}+\frac{1}{6} \log N+B_{i i} \\
B_{i i} & =\text { (const.) }
\end{array}\right\}
$$

Table 1 Test conditions.

Table 3 Longitudinal-wave-velocities in horizontal and vertical directions.

*The sample rock is SAMPLE A obtained at depth of $835 \mathrm{~m}$.
したがつて, 空隙率が変わつてもクラック数 $N$ あ゙あり 変化しない岩石, たとえば圧密されると既存クラックの体 積が小さくなり, その結果, 空陌率が減少するような岩石 では,

$$
\log T_{i i}=-\frac{1}{6} \log D_{i i}+B_{i i}^{\prime}
$$

が成り立ち, 一方 $\overline{a^{3}}$ がほとんど変化しないでクラック数 が空吵率に比例して増加するような岩石, たとえば新しい き裂の発生によつて空吵率が増加したような岩石では，(16) 式を(18)式に代入して

$$
\log T_{i i}=B_{i i}^{\prime \prime}
$$
が成り立つ。

\section{4. 実験方法と試料岩石}

本研究では頁岩の一軸圧縮強度, 引張強度, せ九断強度 および紛波伝ぱ速度を測定した。

一軸圧縮強度は円柱形試験片を破壊するまで荷重を加え て求めた。また, 引張強度は圧裂引張試験により求めた。 せん断強度はプロトジャコノフの一面せん断試験機を用い て求めた。緃波伝ぱ速度はパルス法により求めた。発振器, 受信器には共振周波数 $200 \mathrm{kHz}$ のチタン酸バリウムが使用 されている。試験片の寸法, 荷重速度等はTable 1にまと めて示した。なお, 試料Aでは, まず絽波伝ぱ速度用の試 験片を作成し, 緃波伝ぱ速度を測定した後で試験片を再加 工して圧裂試験片を作成した。試料 Bでは，同一 試験片を用いて, 緥波伝ぱ速度と圧縮強度を測定 した。

使用した頁岩は，2か所より採取したもので

Table 2 に諸元を示す。なお両者とも, 水平方向 と垂直方向とでは異方性を示すが，水平面内にお いてはほぼ等方であつた。水平方向と垂直方向の 維波伝ぱ速度の数值例を Table 3 に示す。

\section{5. 引張強度と縦波伝ぱ速度の実験結果}

Fig. 2 に空吵率 $\lambda$ と $V_{H}^{-2}$ との関係を示す。 $V_{H}$ は

Table 2 Descriptions of sample rocks.

\begin{tabular}{lll}
\hline & $\begin{array}{c}\text { Sample Rock } \\
\text { A }\end{array}$ & \multicolumn{1}{c}{$\begin{array}{c}\text { Sample Rock } \\
\text { B }\end{array}$} \\
\hline Location of Well & $\begin{array}{l}\text { Lincoln } \\
\text { Country, } \\
\text { WVa, USA }\end{array}$ & $\begin{array}{l}\text { Niger, } \\
\text { West Africa }\end{array}$ \\
$\begin{array}{l}\text { Core Sections } \\
\text { (depth in meter) }\end{array}$ & $\begin{array}{l}1.816-850 \\
2.1020-1042\end{array}$ & $20-57$ \\
$\begin{array}{l}\text { Diameter of } \\
\text { Original Core } \\
\text { (cm) }\end{array}$ & 10 & 3.64 \\
$\begin{array}{l}\text { Core Length } \\
\text { per Lot } \\
\text { (cm) }\end{array}$ & 100 & 100 \\
\hline
\end{tabular}

e ）引張り強度を求めるには, 一軸引張り試験を実施するの が望ましいが，簡単のため压裂試験によつた。過去 の研究によれば, 压裂試験の結果は一軸引張り試験の 結果とほぼ一致している。16) 

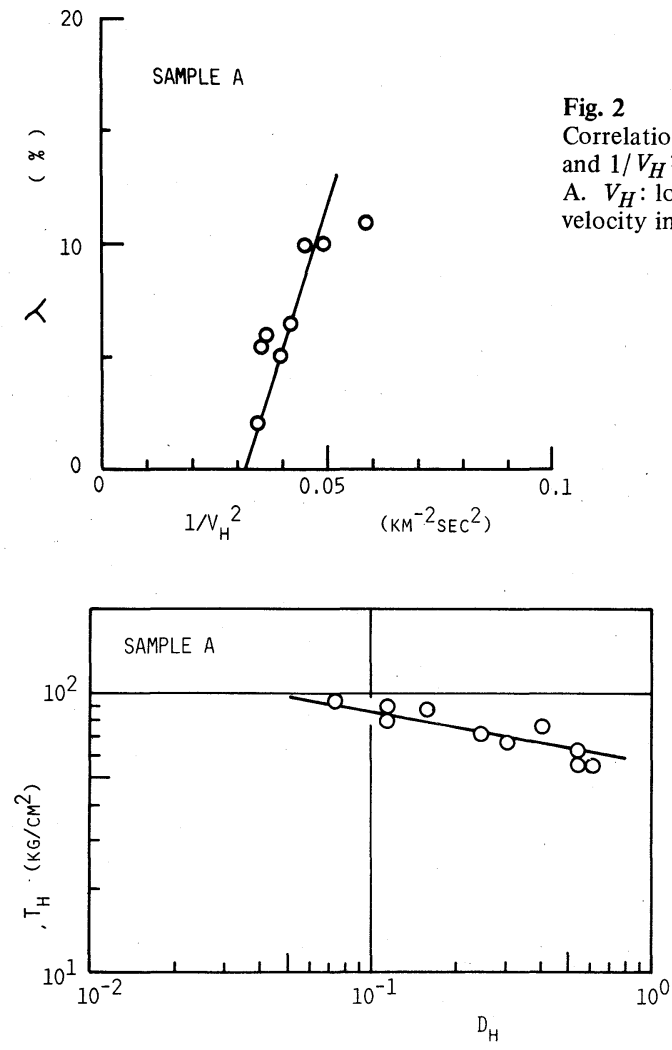

Fig. 3

Tensile-strength change associated with compliance change in horizontal plane, for sample rock $\mathrm{A}$ Tangent of the solid line is $-1 / 6$.

水平方向の縦波伝ぱ速度であり, 図中の一点は同一ブロッ クより切り出された最低 5 個の試験片を用いて測定した結 果の平均值である。ややばらつきはあるが， $\lambda$ と $V_{H}^{-2}$ はほ ぼ直線で近似できる関係を有し，(6)式より分かるように直 線を $\lambda=0$ まで外插することにより $V_{0}$ を求めることができ る。この例の場合， $V_{0}$ は $5.6 \mathrm{~km} / \mathrm{sec}$ であつた。

Fig. 3 に水平方向の引張強度 $T_{H}$ とコンプライアンスの変 化率 $D_{H}$ との関係を, 両対数グラフ上にプロットして示す。 コンプライアンスの変化率 $D_{H}$ は, $V_{H}$ と $V_{0} よ り(4)$ 式を用い て計算した。図より $\log T_{H}$ は $\log D_{H}$ に比例して減少し， その傾きはほぼ-1/6であることがわかる。これよりクラ ック数が空吵率の増加とともにあまり変化しないとして導 いた(19)式がこの場合には成立することがわかる。

次に, 水平方向の引張強度 $T_{H}$ と垂直方向の縱波伝ぱ速度 $V_{V}$ より計算した空吵の存在によるコンプライアンスの変化 率 $D_{V}$ との間に成り立つ関係を調べてみることにする。(19)式 は， $D_{H}$ と $D_{V}$ を用いて次のように変形することができる。

$$
\log T_{H}=-\frac{1}{6} \log D_{V}-\frac{1}{6} \log \frac{D_{H}}{D_{V}}+B_{H}^{\prime} \quad \cdots \text { (21) }
$$

したがつて，(19)式が成り立つ時， $D_{H} / D_{V}$ があまり変化 しないならば $\log T_{H}$ は $\log D_{V}$ に比例して減少し, その傾 きはー1/6であることが予想される。

Fig. 4 にと $V_{V}^{-2}$ との関係を示す。前と同様にして $V_{0}$ を 求めると, この場合には $V_{0}=4.8 \mathrm{~km} / \mathrm{sec}$ となつた。 $V_{V}$ と $V_{0}$ より(4)式を用いて $D_{V}$ を計算した。Fig. 5 に $T_{H}$ と $D_{V}$ と の関係を示す。この場合，ばらつきは Fig. 3 に比べてやや 大きくなるが, $\log T_{H}$ は $\log D_{V}$ に比例して減少し, その 傾きはほぼ-1/6であることがわかる。
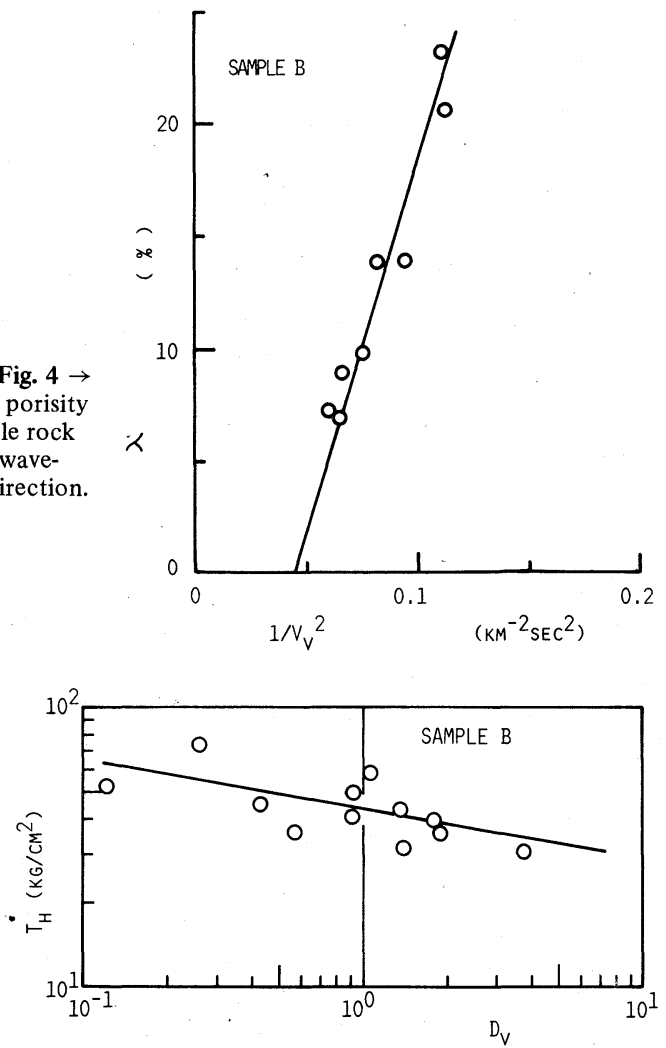

Fig. 5 Tensile-strength change in horizontal plane associated with compliance change in vertical direction, for sample rock B. Tangent of the solid line is $-1 / 6$.

\section{6. 圧縮 強度}

岩石中に構造物を設ける時, 引張強度よりも圧縮強度を 推定することの方がより大切なことが多い。したがつて， 縦波伝ば速度の測定值より, 引張強度のみでなく圧縮強度 も推定できることが望ましい。

修正グリフィス理論によれば，圧縮強度 $C_{0}$ と引張強度 $T_{0}$ の間には，次式の関係が成立する。

$$
C_{0} \propto T_{0} /\left(\sqrt{1+\mu^{2}}-\mu\right)
$$

ここでルは, クラック面間の摩擦係数である。(22式はク ラックの確率分布を考慮していないが，以下では一応(22式 を仮定して議論を進めることにする。

直接せん断試験を行ない, その結果より図式的にルを求 めた。その結果を Fig. 6 に示すが, 摩擦係数は空隙率が増 加してもほとんど変化しない。図に示した例では となる。したがつて(22式が正しいとすれば圧縮強度と引張 強度との比は空隙率とは無関係に一定であることが予想さ れる。このような場合には，圧縮強度も引張強度と同様に 縦波伝ぱ速度より計算したコンプライアンスの変化率 $D$ の $-1 / 6$ 乗に比例して減少するものと考えられる。

Fig. 7 に, 垂直方向の一軸圧縮強度 $C_{0 V}$ と同方向のコン プライアンスの変化率との関係を示す。図より, $C_{0}$ は $D_{V}$ のほぼー $1 / 6$ 乗に比例して減少することがわかる。

\section{7. 結

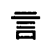

本研究で行なつた範囲内においては, 測定された引張強 


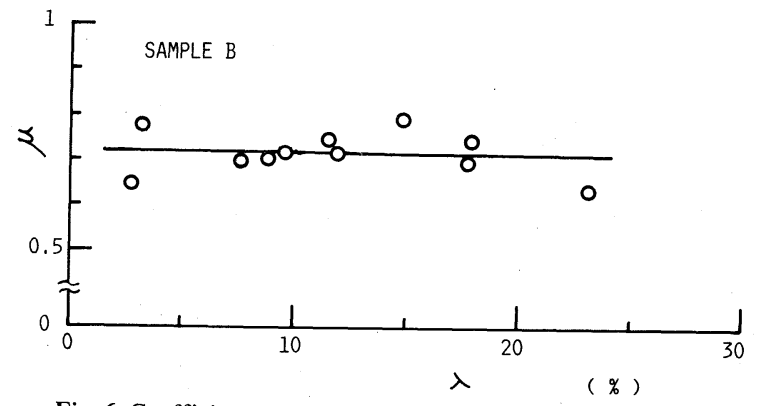

Fig. 6 Coefficient of friction obtained from the results of direct shear test, for sample rock B. Solid line indicates the averaged value.

度あるいは圧縮強度はコンプライアンスの変化率の $-1 / 6$ 乗に比例して減少することがわかつた。この結果は, 空隙 率の増加にともなつてクラックの大きさが大きくなつてゆ くが数はあまり変化しないとした時の理論的な結果と一致 する。コンプライアンスの変化率は, 岩石学的に類似して, 空吵率の異なる 2 種の試料岩石の縦波伝は速度より簡単に 計算できる。したがつて第 5 章で述べた方法等により $V_{0} か ゙$ 求められていれば, $V_{0}$ と現場での縦波伝ぱ速度の測定值よ りコンプライアンスの変化率が計算でき岩石強度を推定す ることができる。

なお，現位置で測定した縦波伝ぱ速度は，地圧の影響に よる変化分を差し引いてからデータ解析する必要がある。 たとえば，試料Aの場合，深さ $h(\mathrm{~m})$ で測定した垂直方向 の縦波伝は速度 $V_{V}^{\prime}(h)$ を, 次式によつて外力のない時の垂 直方向縦波伝ぱ速度 $V_{V}$ に変換した後, 計算を進める必要が ある。

$$
V_{V}=\left(1-0.2 \times 10^{-5} h\right) V_{V}^{\prime}(h)
$$

この例の場合には, (23)式よりわかるように地圧による縦 波伝ぱ速度の変化は小さく, かなりの深さまで補正なしで も十分な精度を保つといえる。

なお, 本研究の一部は著者の一人が米国, 西バージニア 州立大学滞在中に行なつたものであり, その際便宜をはか つて頂いた同大学 Syd S. Peng 博士に感謝の意を表する。

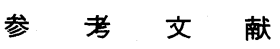

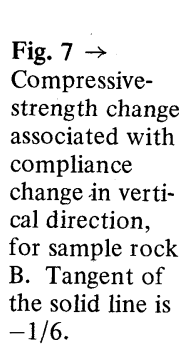

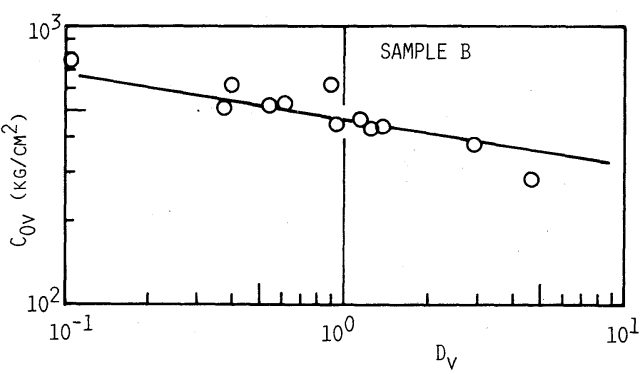

1) Birch, F.: J. Geophys. Res., 66 [7], $2199 \sim 2224$, (1961)

2) Nur, A. : J. Geophys. Res., $76[8], 2022 \sim 2034,(1971$ )

3) $\mathrm{O}^{\prime}$ Connel1, R. J. \& Budiansky, B. : J. Geophys. Res., $79[35], 5412 \sim 5426,(1974)$

4) Soga, N. et al.: J. Geophys. Res., 83 [B9], 4451 4458, ( 1978 )

5) Walsh, J. B. : J. Geophys. Res., 70 [2], 399 411, (1965)

6) Walsh, J. B. : J. Geophys. Res., $70[20], 5249 \sim 5257$, (1965)

7）堀素夫：多孔材料 (近藤連一編著 )，169～180（1973)，技報 堂出版 ( 東京)

8）たとえば, 吉中竜之進：岩の工学的性質と設計・施工への応用 (土 質工学会編 )，325～360（1974）, 土質工学会 (東京)

9）横堀武夫：材料強度学 (第 2 版 )，245～248（1974), 岩波書店 ( 東京)

10）岡村弘之：線形破壊力学入門 (初版)，220,（1976）, 培風館 ( 東京)

11）文献 9), pp. 171 175

12）西松裕一：日本機械学会講演論文集, No. 730-7, 211 218, ( $1973-5-9,10,11$, 東伊豆, 第 5 回シンポジウム, 確率過程論 の機械工学への応用)

13) We ibul1, W. : J. Appl. Mech., 18, 293 297, ( 1951 )

14）西松裕一他：材料, 18 [194], 1019 1025, ( 1969)

15）小林良二・奥村清彦：日本鉱業会誌，87 [999]，407～412, (1971)

16）岡行俊他：日本鉱業会誌, 84 [965], 1465 1469, ( 1968$)$

17) $\mathrm{M}_{\mathrm{c}} \mathrm{C} 1$ intock, F. A. \& Walsh, J. B. : Prco. 4 th U. S. Nat. Cong. Appl. Meck., 1015 1021, (1962)

19) Rogers, L.A. et al. : Rock Mechanics Studies related to Massive Hydraulic Fracturing of Eastern United States Devonian Shales (Final Core Analys is Report), (March 1977), Terra Tek Inc. (Salt Lake City, Utah, U. S.A. )

\section{Evaluation of Rock Strength by Longitudinal-Wave-Velocity Measurement}

\section{from the Stochastic Point of View}

by Seisuke $\mathrm{OKUBO}^{1}$ and Yuichi NISHIMATSU ${ }^{2}$

A theoretical model of rock was proposed to predict the strength of rock by longitudinal-wave-velocity measurement. Rock was assumed to be made of a homogeneous, isotropic, linearly elastic material containing a large number of penny-shaped cracks. The effective compliance of rock that contains cracks was evaluated following the way proposed by Amos Nur. The longitudinal-wave-velocity can be uniquely correlated with the effective compliance. The tensile strength of the rock was also evaluated with the aid of the stochastic process theory and linear fracture mechanics. From the theoretical considerations, the authors developed the foundamental equations by which field velocity data can be interpreted to the tensile strength. The experiments were carried out to measure ultrasonic velocity and tensile strength in laboratory. The theoretical result compared favorably with the experimental data of two kinds of shale.

We also studied the compressive strength of rock based on the modified Griffith theory. The apparent coefficient of friction obtained from data of direct shear tests remains almost constant for the sample rock used. This result indicates that the linear correlation exists between compressive and tensile strengths, therefore the theoretical equations for tensile strength can be used to estimate compressive strength with little modification. The experimental result also showed fine coincidence
with the theoretical results.

(1. Assc. Prof., Dr., Faculty of Engineering, The Univ. of Tokyo,

2. Prof., Dr., Faculty of Engineering, The Univ. of Tokyo ) 